\title{
One thing leads to another: the cascade of obligations when researchers report genetic research results to study participants
}

\author{
Fiona Alice Miller ${ }^{\star, 1,2}$, Robin Zoe Hayeems ${ }^{1}, \mathrm{Li} \mathrm{Li}^{1}$ and Jessica Peace Bytautas ${ }^{1}$
}

Even as debate continues about the putative obligation to proactively report genetic research results to study participants, there is an increasing need to attend to the obligations that might cascade from any initial report. We conducted an international, quasi-experimental survey of researchers involved in autism spectrum disorders (ASD) and cystic fibrosis (CF) genetics to explore perceived obligations to ensure updated information or relevant clinical care subsequent to any initial communication of research results, and factors influencing these attitudes. 5-point Likert scales of dis/agreement were analyzed using descriptive and multivariate statistics. Of the 343 respondents ( $44 \%$ response rate), large majorities agreed that in general and in a variety of hypothetical research contexts, research teams that report results should ensure that participants gain subsequent access to updated information (74-83\%) and implicated clinical services (79-87\%). At the same time, researchers perceived barriers restricting access to relevant clinical care, though this was significantly more pronounced $(P<0.001)$ for ASD $(64 \%)$ than CF (34\%). In the multivariate model, endorsement of cascading obligations was positively associated with researcher characteristics (eg, clinical role/training) and attitudes (eg, perceived initial reporting obligation), and negatively associated with the initial report of less scientifically robust hypothetical results, but unaffected by perceived or hypothetical barriers to care. These results suggest that researchers strongly endorse information and care-based obligations that cascade from the initial report of research results to study participants. In addition, they raise challenging questions about how any cascading obligations are to be met, especially where access challenges are already prevalent.

European Journal of Human Genetics (2012) 20, 837-843; doi:10.1038/ejhg.2012.24; published online 15 February 2012

Keywords: communicating research results; research ethics; autism; cystic fibrosis

\section{INTRODUCTION}

Researchers are increasingly aware of a potential obligation to proactively offer research results to research participants. Ethicists disagree on the existence or extent of any such obligation, with particularly intense debate in the genetics research context, given expanded genomic testing capacity and the proliferation of studies that can generate predictive and family-relevant results. ${ }^{1-6}$ Although many components of this debate have been aired, there has been little discussion of what, if any, cascading obligations might arise as a result of the initial communication of research results.

Cascading obligations are of two sorts. The first concerns the need for updated information about the research result if scientific knowledge changes in a meaningful way. For example, additional research might confirm or refute the finding that was initially reported, changing the personal meaning or clinical utility of having such information in the first instance. In the genetics research context, updated information might be frequently needed, as many initial findings are not supported by later studies. ${ }^{7-10}$ A second cascading obligation involves ensuring that research participants gain access to the clinical care they might need following receipt of results. In the genetics research context, this could include subsequent genetic counselling to fully explain the result after the initial reporting session, genetic testing of family members, or other types of clinical care, including access to drugs, monitoring, or interventions that are implicated by the test result.

Although some commentary has attended to these cascading care obligations, the types of obligation that are acknowledged, and the locus of responsibility for meeting any obligation, varies considerably. For example, Fernandez et $a^{1}$ acknowledge a potential need to ensure that information updates are provided to research participants who receive study results, but they do not address the costs associated with such activities. Renegar et $\mathbf{l}^{11}$ (2006) argue for a limited - though unspecified - responsibility to provide updated information. By contrast, Wade and Kalfoglou suggest that there is a strong obligation to update research participants if original research results are later found to be incorrect. ${ }^{12}$ Further, calling attention to the important relationship between the threshold for disclosure of initial research findings and subsequent obligations to provide updates, they note that a lower threshold for initial reporting is likely to increase the burden of recontact. ${ }^{12}$

In addition, Fernandez et al ${ }^{1}$ endorse an obligation to ensure access to follow-up medical or psychological care or genetic counselling. ${ }^{13}$ Further, they acknowledge the financial implications of these obligations, and lodge the responsibility to ensure and pay for this care with the research enterprise. ${ }^{1,13}$ Others implicate the research enterprise more minimally; for example, to ensure and assume the costs of referral for medical follow-up, ${ }^{14}$ or simply to assume responsibility for 
discussing the need to arrange and pay for medical follow-up during the informed consent process. ${ }^{11}$ By contrast, Pullman and Hodgkinson ${ }^{15}$ advance a more expansive set of cascading clinical responsibilities and lodge responsibility with health care authorities.

Inadequate or inconsistent attention to the obligations that may cascade from the initial communication of research results has implications for individual research participants, and for research and health care policy as a whole. Importantly, the initial communication of research results cannot fulfill the obligations expected of this process - that is, to demonstrate respect for persons, or to ensure the realization of possible benefits ${ }^{16}$ - if the information conveyed is false or its benefits unrealizable. Further, failure to attend to the nature and extent of any cascading obligations obscures policy design questions concerning the coordination and integration of relevant services, and policy ethics questions concerning the just allocation of resources in delivering such care. Who, to be specific, is responsible for meeting any cascading needs, and is sufficient capacity available to address the demand? Is this an appropriate and achievable responsibility of the research team and research enterprise as a whole, including the agencies that fund research? Or can and should these obligations fall to clinical care providers, and the health care systems (whether public or private) that pay for them? And if so, how will the demands generated through research be fairly addressed where access challenges are already prevalent?

To begin to explore these issues, we conducted an international survey of researchers engaged in genetics research for two quite different conditions: the autism spectrum disorders (ASD) and cystic fibrosis (CF). ASD refers to a complex set of developmental disorders that have been the subject of growing public interest as the reported prevalence increases and demand for diagnostic and remediation services outstrip still-developing networks of care. ${ }^{17,18}$ Genetics research on ASD seeks to identify the genetic variants associated with this complex disorder, most of which may confer risk without directly causing the condition. ${ }^{19,20} \mathrm{CF}$, by contrast, is a disorder that has long been known to be caused by mutations in the CFTR gene, ${ }^{21}$ and for which care arrangements are better established. Current genetics research on CF explores genetic modifiers of the CF phenotype, to improve the prognostic power of diagnoses and to seek to develop more targeted treatment options. ${ }^{22}$ Using a quasi-experimental questionnaire design that presents hypothetical vignettes, we sought to explore a range of factors that might influence judgments about researchers' obligations subsequent to the initial communication of research results to individual research participants. Because of our interest in the question of how any such obligations are to be met, we explored researchers' perceptions of access to care for the clinical condition of interest (CF or ASD) in their own jurisdiction, and integrated an access to care variable into the hypothetical vignettes.

\section{MATERIALS AND METHODS}

\section{Sample}

Our methodology has been described in detail elsewhere. ${ }^{23}$ With approval from the University of Toronto and the Hospital for Sick Children Research Ethics Boards, we conducted an international survey of researchers engaged in CF or ASD genetics research in 2009. We identified potential respondents from author lists of relevant scientific articles published between 2005 and 2008. We excluded non-English papers and those that did not reflect original scientific research relevant to CF or ASD genetics. We next limited to authors with publicly available email and postal addresses, generating a final sample of 877 eligible participants (418 ASD and $459 \mathrm{CF}$ ). This information was used to generate our sampling frame and assess non-respondent bias; neither the respondent's jurisdiction, nor details about the respondent's specific type of research, were introduced into our models.

\section{Recruitment and data collection}

We contacted potential participants five times over an 8-week period. ${ }^{24}$ Contacts $1,2,3$ and 5 were by email and directed participants to an online questionnaire, and the 4 th contact was by post and enclosed a paper questionnaire. Participants were provided with an opportunity to receive a non-financial incentive: an executive summary of findings.

\section{Survey instrument}

The survey instrument was designed to test hypotheses about influences on professional judgments regarding researchers' ethical obligations with respect to research results, and included non-experimental and quasi-experimental components. The non-experimental component consisted of: (i) 3 demographic questions about the respondent's primary role in research, professional training, and gender, (ii) 7 practice questions about perceived barriers to gaining access to care in the respondent's jurisdiction, and the role of the respondent's research team in providing updates to participants, and (iii) 12 attitude questions about the respondent's perceived responsibilities toward research participants, beliefs about the potential for harm from provisional scientific information, and beliefs about the role of genes in CF or ASD.

The quasi-experimental component used the factorial survey design to maximize external validity by presenting respondents with true-to-life vignettes, and exploit the principle of random assignment to assess the independent effect of covariates. ${ }^{25-28}$ The vignette related the story of a genetic research team considering what should be done with a recent research finding. Each vignette presented some combination of 10 attributes that, a priori, were deemed relevant to the formation of the professional judgment. ${ }^{6,29}$ We used a fractional factorial approach to reduce the total possible number of vignettes to a number suited to our anticipated sample size and interest in main effects while maintaining an orthogonal and balanced matrix, resulting in 48 unique vignettes, each with a CF and ASD version. These included features of the research finding (eg, effect size, replication status), the research team (eg, CF or ASD, clinical capacity), and the research context (eg, team relationship with research participants, research ethics guidance). To assess the influence of barriers to care on judgments about reporting obligations, we included an attribute for availability of 'comprehensive assessment and treatment services' for individuals with ASD/CF in the jurisdiction where results were being reported (Supplementary Tables 1 and 2 present an attribute list and sample vignette).

Each respondent received two vignettes, one for CF and one for ASD, using the principle of random assignment to establish the order and pairings of vignettes while ensuring an adequate number of respondents completed each unique vignette. Following each vignette, respondents were asked to consider four judgments, two of which related to the decision to report the initial result and have been reported elsewhere. ${ }^{23}$ The focus of this paper concerns judgments about cascading obligations assuming that the initial report had occurred. Specifically, whether the research team should: (i) 'ensure that participants gain access to updated information about this genetic variation (as specified in the vignette), if new research becomes available?', and (ii) 'ensure that participants gain access to the clinical services that might be required as a consequence of receiving this finding (eg, genetic counselling, family testing, and other clinical care)?' These judgments, as well as the attitude questions in the non-experimental component of the questionnaire, were measured using 5-point Likert scales, from strongly agree to strongly disagree (dichotomized into strongly agree or agree versus neutral, disagree, or strongly disagree).

\section{Analysis}

We computed frequency counts and percentages for all independent variables. For univariate tests of difference, we used the chi-square test across samples (CF and ASD), and the $Z$-test for non-independent samples (eg, different beliefs among CF or ASD researchers). A probability level of $<0.05$ was used to determine statistical significance. We next conducted two separate multivariate logistic regression models to explore the effects of all vignette-specific factors (NB: in answering questions for each vignette, respondents judged all attributes included in the vignettes), and identified independent variables specific to the two cascading obligations (see Table 4 for list of covariates in model). We used the forward selection method to develop the models, removing variables where there was evidence of multicollinearity. As different selection procedures can lead to different final models, we re-introduced all variables of interest into the 
final model to test their significance at Pr0.1 (using the Wald statistic). Responses to vignettes were treated as separate observations; thus, the unit of analysis was the judgment provided and not the individual participant. To account for the unknown correlation between the two vignette responses from a given respondent, we used generalized estimating equations. Because of missing data, 7 participants included in descriptive analyses were removed from multivariate analyses.

Finally, we generated an index (scored from 1 to 41) to characterize the degree to which each potential respondent was involved in relevant ASD or CF genetics research and assess the presence of non-responder bias. We scored each of the genetics research publications from which respondents were drawn, differentiating between highly relevant (ie, discovery research, research with human subjects), and less relevant publications (eg, incidence/prevalence studies, Biobank studies). Each participant was then assigned a final score depending on the number of publications and their relevance score ( 1 or 2). All statistical analyses were completed using R ((GNU software): R Foundation for Statistical Computing, Vienna, Austria; version 2.10.1, 2009) and geepack

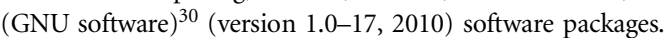

\section{RESULTS}

\section{About respondents}

Response rates and characteristics of respondents. Where we could not locate a valid email and/or postal address after receiving returned mail, we deemed potential respondents ineligible $(n=92)$, leaving a total of 785 eligible respondents. Of these, 343 researchers completed the survey for a total response rate of 44\%: 46.7\% (168 of 360) for ASD researchers and $41.2 \%$ (175 of 425) for CF researchers. Respondents were more likely than non-respondents $(1.8 \mathrm{OR}, 95 \% \mathrm{CI}(1.2,2.7))$ to be authors of discovery and/or human subjects research where issues related to reporting research results to study participants were potentially relevant, compared with incidence/prevalence or Biobank research. Respondents were from around the world: 171 (50\%) from the US, 19 (6\%) from Canada, 126 (37\%) from Europe (comprising 24 from France, 25 from Italy, 26 from the UK, and 9 or fewer from the rest of Europe), and 27 (8\%) from other countries (Australia, Brazil, Chile, Colombia, Hong Kong, India, Israel, Japan, Malaysia, and Taiwan) (Supplementary Table 3 details respondents' jurisdictions). In all, 180 (52\%) respondents held a medical degree (MD or equivalent) and 191 (56\%) held a research-based doctoral degree. In all, $164(48 \%)$ reported a primary research role in molecular genetic analysis, $149(43 \%)$ in clinical interpretation of results, and $114(33 \%)$ in statistical interpretation of research results.

\section{Descriptive data}

Attitudes toward reporting obligations. When asked to consider obligations in general (ie, outside of the specific context described in a vignette), a majority of respondents (74\% of ASD researchers and $83 \%$ of CF researchers) agreed (agreed or strongly agreed) that research teams that report initial research results should ensure that participants gain access to updated information about these variations if new research becomes available. Similarly, $82 \%$ of ASD researchers and $87 \%$ of $\mathrm{CF}$ researchers agreed that research teams should ensure participants gain access to clinical services that might be required as a consequence of receiving the initial research result (Table 1).

As we have reported elsewhere, ${ }^{23}$ a large majority of respondents also agreed that they had an obligation to report a research finding that was judged to be clinically significant $(80.4 \%$ of researchers in total; $80.6 \%$ ASD and $81 \% \mathrm{CF}$ ). However, only small minorities agreed that they had an obligation to report a research finding when there was uncertainty about its clinical significance $(15.2 \%$ ASD and $23.0 \%$ CF). Researchers' attitudes toward an initial obligation to report clinically significant results were not statistically different from attitudes toward an obligation to provide updated information ( $79 \%$ agreed overall; $P=0.22$ ); though they were significantly reduced relative to attitudes toward an obligation of subsequent clinical care ( $84.5 \%$ agreed overall; $P=0.006)$.

In the specific vignette context (ie, the aggregate of responses to the 48 different vignettes per disease), endorsement of the initial communication of the research result was modest. Minorities of respondents (33.5-48.3\%) agreed that researchers had an obligation to report an ASD finding whereas small majorities (53.3-58.0\%) agreed that researchers had an obligation to report a CF finding. By contrast, large majorities of researchers agreed that, following an initial report of the research result to the individual in whom it is identified (and irrespective of whether they felt this should have been reported), the research team is obligated to ensure that participants gain access to: (i) updated information about the research finding, where this becomes available (75-77\% of ASD researchers and $77-82 \%$ of CF researchers), and (ii) clinical services that might be required as a result $(79-81 \%$ of ASD researchers and $85-87 \%$ of CF researchers) (Table 2).

Perception of barriers to receiving clinical care. Researchers perceived a range of barriers restricting access to relevant clinical services for families in their jurisdiction. These included waiting lists for relevant clinical services $(53.0 \%$ ASD and $11.4 \% \mathrm{CF}$ ), lack of relevant clinical expertize $(33.9 \%$ ASD, $11.4 \% \mathrm{CF})$ or the cost of relevant clinical services $(48.2 \%$ ASD and $26.9 \% \mathrm{CF})$. Taken together, $63.7 \%$ of ASD researchers perceived that there were barriers to receiving relevant clinical care (ie, any of the three specific barriers identified) for families in their jurisdiction, whereas only $33.7 \%$ of $\mathrm{CF}$ researchers

Table 1 General researcher attitudes regarding cascading obligations

\begin{tabular}{|c|c|c|c|c|}
\hline & & $A S D, N(\%)$ & $C F, N(\%)$ & $\chi^{2}, P$-value \\
\hline \multicolumn{5}{|c|}{ In general, I believe that if my research team decides to report a genetic research finding to individuals in whom it is identified, my team is obligated to ... } \\
\hline ... ensure that participants gain access to updated & $\mathrm{SA} / \mathrm{A}$ & $125(74.40)$ & $146(83.43)$ & Mid-P exact, \\
\hline $\begin{array}{l}\text { information about this genetic variation, if new research } \\
\text { becomes available }\end{array}$ & $\mathrm{SD} / \mathrm{D} / \mathrm{N}$ & $43(25.60)$ & $29(16.57)$ & 2-tail: 0.042 \\
\hline ... ensure that participants gain access to the clinical & SA/A & $137(81.55)$ & $153(87.43)$ & Mid- $P$ exact, \\
\hline $\begin{array}{l}\text { services that might be required as a consequence of } \\
\text { receiving this finding (eg, genetic counseling, family } \\
\text { testing, other clinical care) }\end{array}$ & $\mathrm{SD} / \mathrm{D} / \mathrm{N}$ & $31(18.45)$ & $22(12.57)$ & 2-tail: 0.136 \\
\hline
\end{tabular}

Abbreviations: A, agree; ASD, autism spectrum disorders; CF, cystic fibrosis; D, disagree; N, neutral; SA, strongly agree; SD, strongly disagree. 
Table 2 Perceived initial and cascading obligations: vignette response frequencies

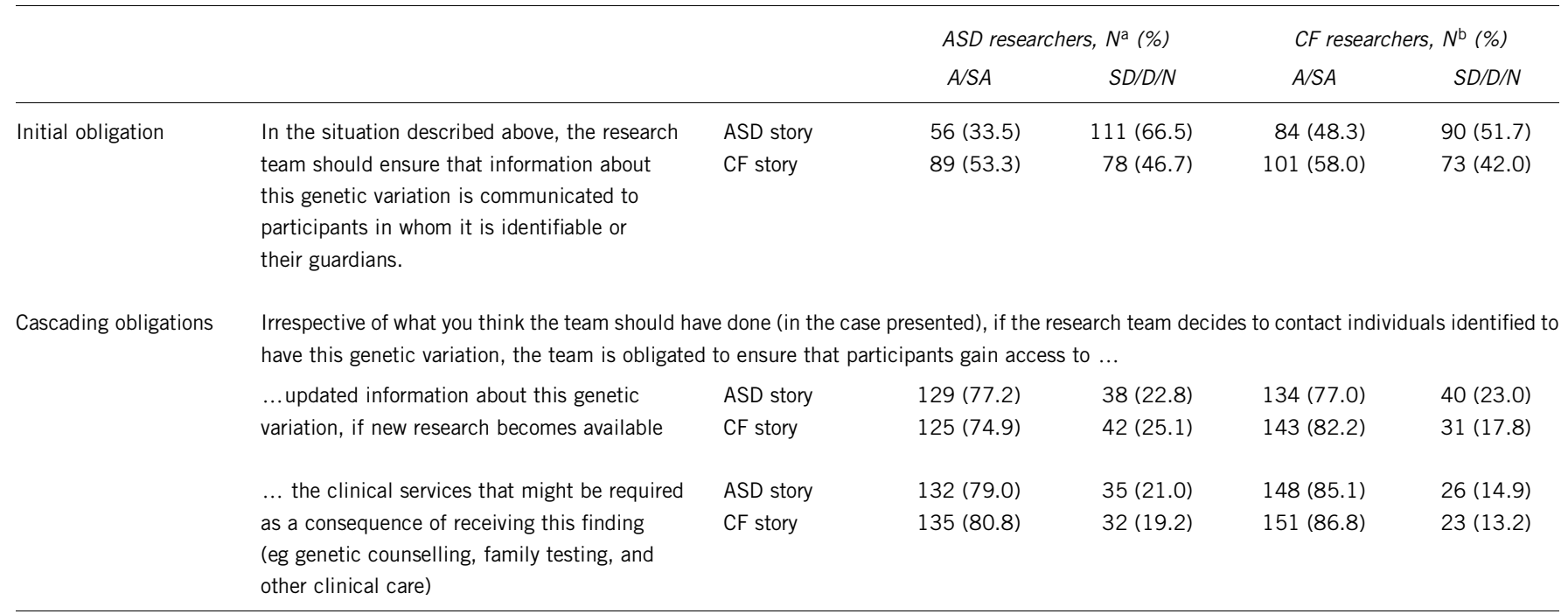

Abbreviations: A, agree; $D$, disagree; $N$, neutral; $S A$, strongly agree; $S D$, strongly disagree.

aMissing data from one CF (cystic fibrosis) researcher.

bMissing data from one ASD (autism spectrum disorders) researcher.

Table 3 Researcher perception of own context: adequacy of clinical services in own jurisdiction

\begin{tabular}{|c|c|c|c|c|}
\hline & & $A S D, N(\%)$ & $C F, N(\%)$ & $\chi^{2}, P$-value \\
\hline \multicolumn{5}{|c|}{$\begin{array}{l}\text { With respect to the adequacy of clinical services in your jurisdiction for individuals with ASD/CF, There are barriers to obtaining relevant clinical services for (CF/ASD) becaus } \\
\text { of ... }\end{array}$} \\
\hline \multirow[t]{2}{*}{ (i) ... waiting lists for relevant clinical services } & Yes & $89(53.0)$ & $20(11.4)$ & $<0.001$ \\
\hline & No/don't know & $79(47.0)$ & 155 (88.6) & \\
\hline \multirow[t]{2}{*}{ (ii) $\ldots$ the lack of relevant clinical expertise ${ }^{a}$} & Yes & 57 (33.9) & $20(11.4)$ & $<0.001$ \\
\hline & No/don't know & $111(66.1)$ & 154 (88.0) & \\
\hline \multirow[t]{2}{*}{ (iii) ... the cost of relevant clinical services } & Yes & $81(48.2)$ & 47 (26.9) & $<0.001$ \\
\hline & No/don't know & $87(51.8)$ & $128(73.1)$ & \\
\hline \multirow[t]{2}{*}{ Any barriers: (i) or (ii) or (iii) } & Yes & 107 (63.7) & 59 (33.7) & $<0.001$ \\
\hline & No/don't know & $61(36.3)$ & $116(66.3)$ & \\
\hline
\end{tabular}

Abbreviations: ASD, autism spectrum disorders; CF, cystic fibrosis.

aMissing data from one CF researcher.

reported that there were barriers to care; these differences are highly statistically significant $(P<0.001)$ (Table 3$)$.

\section{What explains cascading obligations? Multivariate models}

Influences on the perceived obligation to provide updated information. Several beliefs were associated with the perceived obligation to ensure access to updated information. Respondents who agreed that, in general, they had an obligation to report clinically significant findings to individual research participants were more than twice as likely (OR $2.5,95 \%$ CI $1.5,4.3$ ) as those who did not endorse this obligation, to perceive a need to ensure access to updated information. Male respondents were half as likely (OR $0.55,95 \%$ CI $0.33,0.91$ ) as female respondents to perceive this obligation and researchers with a medical degree were more likely (OR 1.8, 95\% CI 1.1, 2.9) than those without such professional qualifications to perceive this obligation (Table 4).

Only one vignette attribute, reflecting the scientific robustness of the hypothetical finding, was retained in the final model. Specifically, respondents were less likely to perceive an obligation to provide updated information where the finding had not previously been reported than when the finding had been replicated multiple times in independent research groups, though this effect was only statistically significant at the $P=0.1$ level.

Influences on the perceived obligation to provide subsequent care. As with the experimental model for updated information, respondents who perceived the general obligation to report clinically significant findings were twice as likely (OR 2.0, 95\% CI 1.1, 3.7) as those who did not to endorse an obligation to ensure subsequent clinical care. In addition, male respondents were half as likely (OR 0.51, 95\% CI 0.30, 0.90) as female respondents to perceive this obligation. Respondents with a primary research role in the clinical interpretation of research results were twice as likely as those without this role (OR 2.1, 95\% CI $1.2,3.7)$, whereas those with a primary role in the statistical and epidemiological interpretation of findings were almost half as likely (OR $0.61,95 \%$ CI $0.38,0.97)$ as those without this role, to endorse this obligation.

Of the vignette attributes, only the measure of scientific robustness had a significant impact on responses. Specifically, respondents were 
Table 4 Associations with perceived obligation to provide updated information and subsequent care: main effects multivariate GEE models ${ }^{a}$

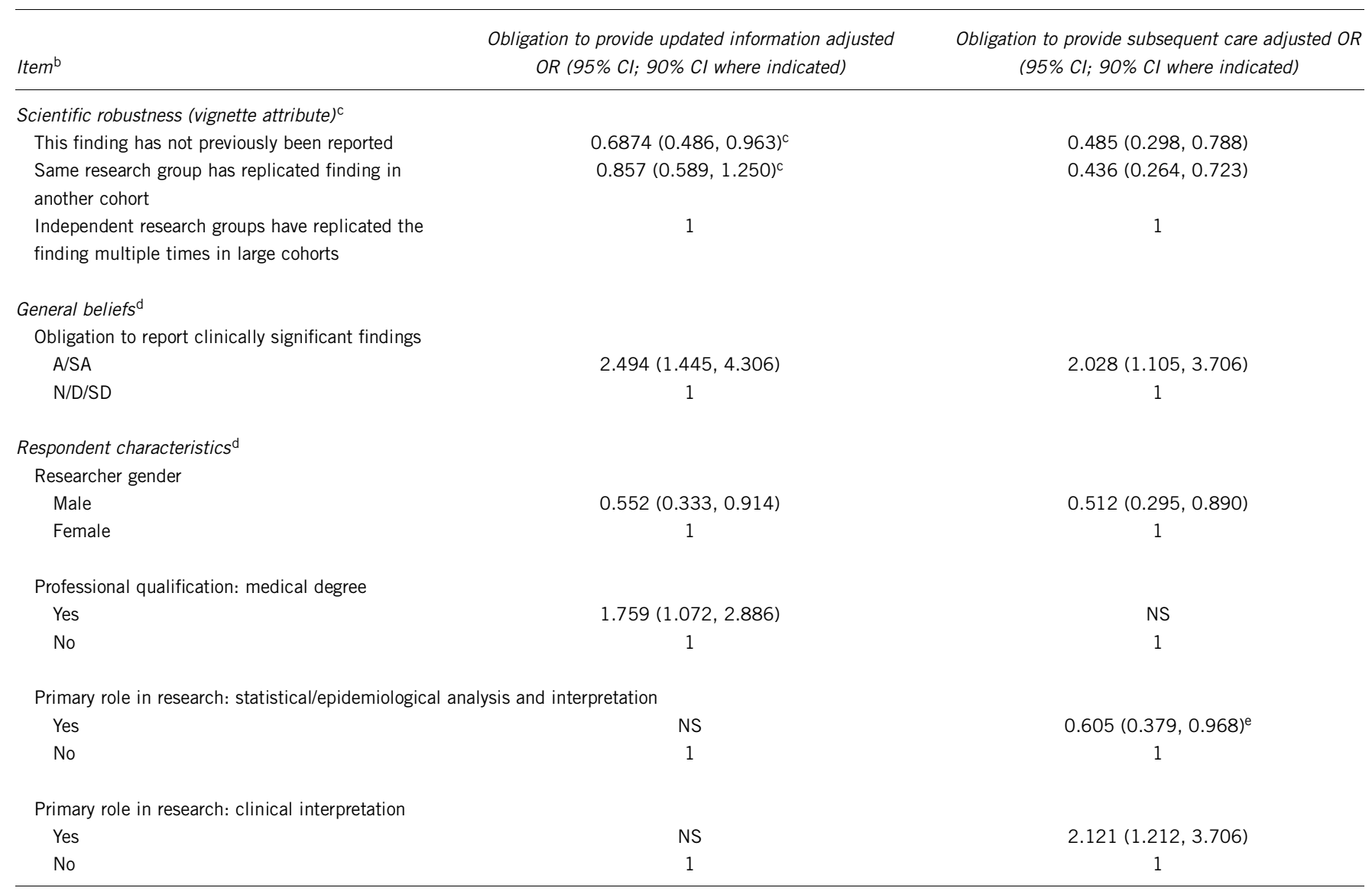

Abbreviations: A, agree; D, disagree; N, neutral; NS, not statistically significant; SA, strongly agree; SD, strongly disagree.

aTo account for the unknown correlation between two vignette responses from each respondent, we used generalized estimating equations (GEE).

bData missing from four ASD (autism spectrum disorders) researchers and three CF (cystic fibrosis) researchers.

cVignette attribute. In the interests of space, we report only the vignette attributes that were retained in the final model.

dIndependent variables (ie, not in vignette). In the interests of space, we report only the independent variables that were retained in the final model; those included in model but not statistically significant at $P<0.1$ are as follows: Disease community of researcher (ASD/CF); primary role in research, molecular interpretation (yes/no); professional qualification, research doctoral degree (yes/no); perception of barriers to clinical services in own jurisdiction (yes/no or don't know); belief that research team has obligation to report results not deemed clinically significant (agree or strongly agree/neutral, disagree or strongly disagree); belief that provisional scientific information is potentially harmful for research participants (agree or strongly agree/neutral, disagree or strongly disagree). e $90 \% \mathrm{Cl}$.

half as likely to perceive an obligation to provide subsequent care when the finding had not previously been reported (OR $0.49,95 \%$ CI $0.30,0.80$ ) or when the same research group had replicated the finding in another cohort (OR 0.44, 95\% CI 0.26, 0.72) than when the finding had been replicated multiple times in independent research groups.

\section{DISCUSSION}

Our findings suggest that researchers endorse what we term 'cascading' obligations, with more endorsement of an obligation of subsequent clinical care than of updated information. Further, the perceived obligation to address these cascading commitments is equal to or greater than the perceived obligation to report clinically significant findings in the first instance, and is much greater than any perceived obligation to report research results where clinical significance is uncertain. This is suggested by general attitudes, and in the aggregate of attitudes for each of the hypothetical vignettes where - irrespective of the attributes that were varied in each vignette (eg, disease type, scientific robustness of result, and research environment) - researchers were less disposed to the initial reporting obligation than to the subsequent obligations of information and care that ensue.
Our models add insight to these descriptive findings, exposing some factors that may influence researchers' attitudes regarding cascading obligations. Among vignette-specific factors, only one was retained in the final models: Where reported findings were less robust (ie, less independence of replication and/or less replication), respondents had a reduced commitment to cascading obligations. These associations run contrary to the suggestion by Wade and Kalfoglou ${ }^{12}$, that a lower initial threshold necessitates a higher subsequent commitment. This finding thus raises important questions about the relationship that should obtain between initial and cascading obligations.

Non-vignette factors also influenced researchers' perceptions of cascading obligations. Specifically, those who felt obliged to report clinically significant research results in the first instance were more likely to endorse cascading obligations. An additional and related finding is that perceived obligations to ensure access to information and care were more likely among those with a clinical orientation and less likely among those with a statistical/epidemiological role. Taken together, these findings confirm to what we have shown with respect to attitudes toward an initial reporting obligation, ${ }^{17,23}$ suggesting that the more clinically relevant the result or clinically-disposed the respondent, the greater is the commitment to the obligation. 
Despite the markedly different clinical contexts tested, researchers' beliefs about the two cascading obligations were not influenced by the nature of the disease (ASD or CF), the researchers' field of study (ASD or CF), or by hypothetical (ie, in the vignette) or perceived actual (ie, in researchers' own jurisdiction) barriers to care. However, almost two-thirds of ASD researchers perceived barriers to clinical care for ASD in their jurisdiction, whereas only one-third of CF researchers perceived such barriers. These data highlight the fact that cascading care obligations may exist in the context of sometimes-significant access barriers. Yet these data do not provide insight into how any such obligations might actually be discharged. Our survey was not designed to answer questions about the locus of responsibility for ensuring access to subsequent information or care, assuming that cascading obligations do arise. Indeed, because this was an international survey of researchers operating with diverse care arrangements, we were necessarily vague about who might be responsible (ie, whether public or private health insurers, research teams, or research participants themselves). Nonetheless, our data point toward both the challenge of access - who is responsible for ensuring information and care - and the challenge of fairness in access - will access for research participants be fair relative to non-participants with similar needs?

\section{CONCLUSION}

Our data suggest that researchers perceived the existence of obligations to research participants that cascade from any initial reporting obligation and did so in equal or greater measure to their commitment to the initial disclosure of clinically significant findings. Attitudes toward cascading obligations were unaffected by access challenges for relevant care that may already exist, suggesting a need to carefully consider how any cascading obligations might be met fairly.

Although descriptive data can inform normative argument, the normative significance of this research is not obvious. We think it notable, however, that researchers expressed at least as much support for cascading obligations as they did for an initial reporting obligation, despite current ethical attention that favours the latter. We therefore call for focused attention to the issue of cascading information and care obligations among proponents of an initial reporting obligation, and among researchers considering an initial disclosure. In addition, we argue for sustained policy discussion about the service arrangements, funding mechanisms, and human resources that might be called upon to ensure equitable and appropriate access to such care.

\section{LIMITATIONS}

The study reports findings from the authors of ASD or CF genetics research publications, and therefore necessarily represents this selected population. Further, the representativeness of the data is limited by the $44 \%$ response rate. This limitation is balanced by the international nature of the survey, and by the fact that, according to the index of involvement that we generated, respondents were more involved than non-respondents in the type of research where issues related to reporting results to research participants are most likely to arise. Further, the complexity of our study design combined with a lowresponse rate limited our power to detect all potentially meaningful effects or to interpret two-way or higher order interacting effects. Further, although variations in practices and attitudes may be associated with researchers' jurisdictions or their specific type of research (eg, discovery, translational, clinical, and so on), we were unable to assess these effects in our models. Interested in understanding both what cascading obligations exist and how best to attend to these, our findings only gesture towards factors that warrant further study.

\section{CONFLICT OF INTEREST}

The authors declare no conflict of interest.

\section{ACKNOWLEDGEMENTS}

We thank our study participants for taking the time to complete our survey as well as Genome Canada for funding this project. We also thank our clinical collaborators in the context of cystic fibrosis genetic research (Drs Peter Durie, Julian Zielenski, and Mary Corey) and autism spectrum disorders genetic research (Drs Stephen Scherer, Peter Szatmari, Wendy Roberts, and Lonnie Zwaigenbaum). Fiona A Miller is supported by a New Investigator Award from the Canadian Institutes of Health Research (80495). Robin Z Hayeems has been supported by a CADRE Postdoctoral Fellowship from the Canadian Institutes of Health Research and the Canadian Health Services Research Foundation, and is now supported by a CF Canada Research Fellowship. Sponsors' support for this work should not imply endorsement of the conclusions, for which the authors retain sole responsibility.

1 Fernandez C, Kodish E, Weijer C: Informing study participants of research results: an ethical imperative. IRB 2003; 25: 12-19.

2 Shalowitz D, Miller F: Disclosing individual results of clinical research: implications of respect for participants. JAMA 2005; 294: 737-740.

3 Miller FA, Christensen R, Giacomini M, Robert J: Duty to disclose what? Querying the putative obligation to return research results to participants. JME 2008; 34: 210-213.

4 Meltzer L: Undesirable implications of disclosing individual genetic results to research participants. Am J Bioeth 2006; 6: 28-30.

5 Ossorio P: Letting the gene out of the bottle: a comment on returning individual research results to participants. Am J Bioeth 2006; 6: 24-25.

6 Miller FA, Hayeems RZ, Bytautas JP: What is a meaningful result? Disclosing the results of genomic research in autism to research participants. Eur J Hum Genet 2010; 18: 867-871.

7 Ioannidis J: Expectations, validity, and reality in omics. J Clin Epidemiol 2010; 63: 945-949.

8 Siontis K, Patsopoulos N, loannidis J: Replication of past candidate loci for common diseases and phenotypes in 100 genome-wide association studies. Eur J Hum Genet 2010; 18: 832-837.

9 Ioannidis J: Non-replication and inconsistency in the genome-wide association setting. Hum Hered 2007; 64: 203-213.

10 Hirschorn J, Lohmueller K, Byrne E, Hirschhorn K: A comprehensive review of genetic association studies. Genet Med 2002; 4: 45-61.

11 Renegar G, Webster $C$, Stuerzebecher $S$ et al: Returning genetic research results to individuals: points to consider. Bioethics 2006; 20: 24-36.

12 Wade $C$, Kalfoglou A: When do genetic researchers have a duty to recontact study participants? Am J Bioeth 2006; 6: 26-27.

13 Fernandez C, C S, Weijer C: Considerations and costs of disclosing study findings to research participants. CMAJ 2004; 170: 1417-1419.

14 Bookman E, Langehorne A, Eckfeldt J et al: Reporting genetic results in research studies: summary and recommendations of an NHLBI Working Group. Am J Med Genet 2006; 140A: 1033-1040.

15 Pullman D, Hodgkinson K: Genetic knowledge and moral responsibility: ambiguity at the interface of genetic research and clinical practice. Clin Genet 2006; 69: 199-203.

16 Miller FA, Hayeems RZ, Li L, Bytautas JP: What does 'respect for persons' require? Attitudes and reported practices of genetics researchers in informing research participants about research. JME 2012; 38: 48-52.

17 Kim S-J, Silva R, Flores C et al: A quantitative association study of SLC25A12 and restricted repetitive behavior traits in autism spectrum disorders. Mol Autism $2011 ; 2: 8$.

18 Chiri G, Warfield M: Unmet need and problems accessing core health care services for children with autism spectrum disorder. Matern Child Health J 2012; e-pub ahead of print 3 February 2012.

19 Szatmari P, Paterson A, Zwaigenbaum L, Roberts W, Briaj J, Liu X-Q: Mapping autism risk loci using genetic linkage and chromosomal arrangements. Nat Rev Genet 2007; 39: 319-328.

20 Weiss L, Shen Y, Korn J, Arking D, Miller D, Fossdal R: Association between microdeletion and microduplication at 16p11.2 and autism. NEJM 2008; 2008: 667-675.

21 Kerem B, Rommens J, Buchanan J et al: Identification of the cystic fibrosis gene: genetic analysis. Science 1989; 245: 1973-1980.

22 Park J, Yung R, Stefanowicz D et al: Cystic fibrosis modifier genes related to Pseudomonas aeruginosa infection. Genes Immun 2011; 12: 370-377.

23 Hayeems RZ, Miller FA, Li L, Bytautas JP: Not so simple: A quasi-experimental study of how researchers adjudicate genetic research results. Eur J Hum Genet 2011; 19: 740-747.

24 Dillman D, Smyth J, Christian L: Internet, Mail, and Mixed-Mode Surveys: The Tailored Design Method, 3rd ed. Hoboken, New Jersey: John Wiley \& Sons, Inc, 2009. 
25 Schwappach D, Koeck C: What makes an error unacceptable? A factorial survey on the disclosure of medical errors. Int J Quality Health Care 2004; 16: 317-326.

26 Applegate B, Turner M, Sanborn JJ, Latessa E, Moon M: Individualization, criminalization, or problem resolution: a factorial survey of juvenile court judges' decisions to incarcerate youthful felony offenders. Justice Quarterly 2000; 17: 309.

27 O'Toole R, Webster S, O'Toole A, Lucal B: Teachers' recognition and reporting of child abuse: a factorial survey. Child Abuse and Neglect 1999; 23: 1083-1101.
28 Goldman H, Rachuba L, Van Tosh L: Methods of assessing mental health consumers' preferences for housing and support services. Psychiatr Serv 1995; 46: 169-172.

29 Miller FA, Giacomini M, Ahern C, Robert J, de Laat S: When research seems like clinical care: a qualitative study of the communication of individual cancer genetic research results. BMC Medical Ethics 2008; 9: 4.

30 Hojsgaard S, Halekoh U, Yan J: The R package geepack for generalized estimating equations. J Stat Softw 2006; 15: 1-11.

Supplementary Information accompanies the paper on European Journal of Human Genetics website (http://www.nature.com/ejhg) 